\title{
Size and long-term growth trends of Endangered fish-eating killer whales
}

\author{
Holly Fearnbach ${ }^{1, *}$, John W. Durban ${ }^{2,3}$, Dave K. Ellifrit ${ }^{2}$, Ken C. Balcomb III ${ }^{2}$ \\ ${ }^{1}$ School of Biology, University of Aberdeen, Lighthouse Field Station, Cromarty, Ross-shire IV11 8YJ, UK \\ ${ }^{2}$ Center for Whale Research, Friday Harbor, Washington 98250, USA \\ ${ }^{3}$ Protected Resources Division, Southwest Fisheries Science Center, National Marine Fisheries Service, \\ National Oceanic and Atmospheric Administration, 8604 La Jolla Shores Drive, La Jolla, California 92037, USA
}

\begin{abstract}
The Endangered southern resident population of killer whales Orcinus orca has been shown to be food-limited, and the availability of their primary prey, Chinook salmon Oncorhynchus tshawytscha, has been identified as a key covariate for the whales' individual survival and reproduction. We collected aerial photogrammetry data on individual whale size, which will help to better inform energetic calculations of food requirements, and we compared size-at-age data to make inferences about long-term growth trends. A helicopter was used to conduct 10 flights in September 2008, resulting in 2803 images from which useable measurements were possible for 66 individually identifiable whales, representing more than three-quarters of the population. Estimated whale lengths ranged from $2.7 \mathrm{~m}$ for a neonate whale in its first year of life, to a maximum of $7.2 \mathrm{~m}$ for a $31 \mathrm{yr}$ old adult male. Adult males reached an average (asymptotic) size estimate ( $\pm \mathrm{SE}$ ) of $6.9 \pm 0.2 \mathrm{~m}$, with growth slowing notably after the age of $18 \mathrm{yr}$; this was significantly larger than the asymptotic size of $6.0 \pm 0.1 \mathrm{~m}$ for females, which was reached after the earlier age of $15 \mathrm{yr}$. Notably, there was no overlap between the ranges of estimated sizes of adult males (6.5 to $7.2 \mathrm{~m}$ ) and females (5.5 to $6.4 \mathrm{~m})$. On average, older adults $(>30 \mathrm{yr})$ were $0.3 \mathrm{~m}(\mathrm{n}=14, \mathrm{p}=0.03)$ and $0.3 \mathrm{~m}(\mathrm{n}=5, \mathrm{p}=0.23)$ longer than the younger whales of adult age, for females and males, respectively; we hypothesize that a long-term reduction in food availability may have reduced early growth rates and subsequent adult size in recent decades.
\end{abstract}

KEY WORDS: Killer whale $\cdot$ Photogrammetry $\cdot$ Size $\cdot$ Growth $\cdot$ Salmon

\section{INTRODUCTION}

Data on individual size of organisms can be used to address fundamental questions with respect to conservation management of Endangered populations. These fundamental questions include identification of taxonomic status (Perryman \& Lynn 1993, Perryman \& Westlake 1998, Pitman et al. 2007), assessment of health (Choquenot 1991, Landete-Castillejos et al. 2002, Perryman \& Lynn 2002), estimation of energetic requirements (Williams et al. 2004, Noren 2011), and identification of key life-history and demographic patterns (Choquenot 1991, Koski et al. 1992, Perryman \& Lynn 1993, Read et al. 1993, Lee \& Moss 1995, Flamm et al. 2000, Shrader et al. 2006, Breuer et al. 2007). Notably, an individual's adult size is influenced by environmental factors during early growth (Metcalfe \& Monaghan 2001, Catchpole et al. 2004), and therefore information on size and size trends can be used to infer responses to environmental variability, such as the effects of nutritional stress due to limited food availability (Choquenot 1991, Catchpole et al. 2000, Trites \& Donnelly 2003).

Free-ranging cetaceans at sea represent a challenge for collecting morphometric data, although live-capture operations have been possible for some smaller species (e.g. Read et al. 1993). Photogrammetric approaches implemented from boat-based platforms have provided a simple alternative for measuring body features exposed above the surface (Durban \& Parsons 2006, Jaquet 2006, Webster et. al. 2010), but precise estimates 
of full body size typically require an aerial platform to obtain through-water images from directly above a whale (Koski et al. 1992, Perryman \& Lynn 1993, 2002, Perryman \& Westlake 1998). Helicopter platforms have proven to be extremely well suited to providing precise photogrammetric measurements of cetaceans (e.g. Pitman et al. 2007), due largely to the ability of helicopters to hover at a fixed (and known) altitude and make relatively subtle adjustments in location to remain directly overhead of target animals. Although helicopters have been deployed for this purpose from pelagic research ships (Perryman \& Lynn 1993), they offer particular utility for aerial photogrammetry of accessible coastal populations that can be surveyed during short (fuelrestricted) helicopter flights with minimal open-water flying.

The Endangered southern resident population of killer whales Orcinus orca is one of the most accessible populations of cetaceans. This distinct population comprises $<100$ whales that return to the coastal waters of Washington State (USA) and British Columbia (Canada) each summer to feed on returning runs of Pacific salmon (Ford et al. 2000, 2009, Krahn et al. 2004, Ford \& Ellis 2006). As a result of their coastal habitat, this is one of the best-studied mammalian populations: population size, individual life histories, and demographics have been monitored through an annual photo-identification census of individuals dating back to the early 1970s (Bigg et al. 1990, Olesiuk et al. 1990, Ford et al. 2000). This monitoring has revealed changes in population size (Parsons et al. 2009) which have formed the basis for listing this population as 'endangered' under the Species at Risk Act in Canada and the Endangered Species Act in the USA.

Long-term prey-habit studies of southern resident killer whales have shown distinct prey specialization on Chinook salmon Oncorhynchus tshawytscha during the summer months (Ford \& Ellis 2006), and recent analysis of long-term demographic data has shown this whale population to be food-limited, with declines in survival (Ford et al. 2009), fecundity (Ward et al. 2009), and social cohesion (Parsons et al. 2009) during years with low Chinook salmon availability. The aims of the present study were (1) to collect aerial photogrammetry data on individual size, which will help to better inform energetic calculations of food requirements for this population (Noren 2011), and (2) to compare sizeat-age data to make inferences about long-term growth trends.

Existing size data are available for $>30$ individuals from this population that were captured in a livecapture fishery for exhibition in aquaria, conducted in the 1960s and early 1970s (Bigg \& Wolman 1975, Olesiuk et al. 1990). However, this fishery selected for physically immature animals (Olesiuk et al. 1990), and age data are not available, constraining a detailed assessment of the full size-at-age profile and preventing use of these data for examining size trends. A key feature of our approach was the use of an established longterm photo-identification catalog of individuals (Ford et al. 2000) to match aerial photographs and measurements to individual whales of known sex and age (Olesiuk et al. 1990, Ford et al. 2000). Aerial photographic surveys were directed in real-time by boat-based photo-identification surveys to maximize the coverage of different individuals and age/sex classes within the population.

\section{MATERIALS AND METHODS}

Field methods. We used a Robinson R44 Clipper helicopter to survey for whales from an airport at Friday Harbor, Washington State, during September 2008. To minimize search time, flights were only conducted on days when southern resident killer whales had been reported to be in the area and a research boat had established contact with the whales. Guided by communications from the boat, the helicopter searched for whales at an altitude of around $1000 \mathrm{ft}$ $(\sim 305 \mathrm{~m})$, with descents to as low as $750 \mathrm{ft}(\sim 229 \mathrm{~m})$ to photograph whales. J.W.D. acted as an onboard guide to the helicopter pilot, using communication from the research boat to direct the helicopter over different target whales, to maximize the coverage of different individuals and age/sex classes within the population. Real-time whale identifications were made from the boat by D.K.E., who has $>25$ yr of experience in recognizing individual southern resident killer whales at sea. The helicopter then hovered to hold position over each target whale until the photographer (H.F.) had captured suitable images of the whale.

The photographer was positioned in the passenger seat behind the pilot so that both could obtain a similar view from the same side of the helicopter, which facilitated positioning directly overhead of the whale. Wearing a seat harness, the photographer then leaned out of the open passenger door to shoot photographs vertically down on the target whale. A bubble-level was attached to the back of a hand-held digital SLR camera (Nikon D300), to ensure that the camera was orientated vertically, while the photographer used continuous shooting mode to capture as many images as possible of the surfacing whale. Photographs were taken when the whale was at the water surface and parallel to the water surface. High-quality JPEG images were shot at a resolution of $4288 \times 2848$ pixels (13.1 megapixel resolution) in preference to raw images in order to maximize the number of frames per 
second (to $\sim 6$ frames $\mathrm{s}^{-1}$ ). This ensured that the most elongated position of the whale was captured on each surfacing. A fixed focal length $180 \mathrm{~mm}$ f2.8 AF Nikkor lens was used either with or without a $1.4 \times$ Kenko Pro extender, to achieve a realized focal length of either 378 or $270 \mathrm{~mm}$ (after accounting for the focal length factor of 1.5 inherent in the digital image sensor of the camera).

The altitude was recorded at $1 \mathrm{~s}$ intervals throughout each flight using an onboard Garmin GPSMap 396 aerial GPS unit. This WAAS-enabled (WAAS: Wide Area Augmentation System) differential GPS continuously received parallel signals from 12 satellites, and also calibration signals from shore stations, to compute and update the position with advertised error of $<3 \mathrm{~m}$ (www8.garmin.com/aboutGPS/waas.html). The GPS and camera time were synchronized so that each image could be linked to a specific altitude using a relational database. To ensure that these 2 time stamps were precisely matched, a Blue2Can Bluetooth receiver on the camera received wireless time signals from a second GPS unit (Holux M241), and this time was directly embedded into the metadata associated with each image. This ensured that both the altitudelinked aerial GPS time and the camera time were derived from GPS signals, rather than relying on the pre-set camera clock that had to be manually updated.

Photographic processing. Prior to measuring, every photograph was examined by D.K.E. to match the image to an individual whale. The digital photographs were displayed on a 22-inch $(56 \mathrm{~cm})$ high-resolution flat panel monitor and were viewed through ACDSee photo manager (www.acdsee.com/). Photographs were linked to known individuals (of known age and sex class) by matching saddlepatch pigmentation patterns (Fig. 1) of individual whales to the long-term (33 yr) identification catalog (Ford et al. 2000, K. C. Balcomb unpubl. data). Photographic matches to the catalog were validated, where possible, by examining identification photographs obtained during the coordinated boat-based operations, and also using boat-based records of group composition and spacing at times coincidental to the aerial photographs.

Photographs of identified whales were then re-examined by H.F. for measurement purposes, again using a 22-inch $(56 \mathrm{~cm})$ high-resolution monitor. ACDSee photo manager was first used to perform a second check of the individual identities by cross-referenc- ing the identification catalog, and then to select the best image(s) from each surfacing sequence of an identified whale. To ensure high quality, only images that were deemed to be vertical and with the whale in straight orientation (i.e. body axis of the whale was not tilted) were selected, and the most elongated image(s) of each whale was then chosen from the filtered set from each surfacing. The freely available software ImageJ (http://rsbweb.nih.gov/ij/) was used to measure the distance (in pixels) between the tip of upper jaw to the notch in the flukes (e.g. Pitman et al. 2007). All measurements in pixels were first converted to a true measurement based on the actual width of the digital sensor $(0.036 \mathrm{~m})$ and the dimensions of this sensor width in pixels (4288). These measured distances were then converted to true lengths based on the scale of each image, which was calculated from the known altitude and realized lens focal length (scale $=$ altitude/focal length). Images and associated data on individual identification, individual age, focal length, and size measurements were imported into a Microsoft Access relational database, where they were linked to the GPS data on altitude based on the time matches.

To test the variability in our technique, we used aerial photographs to estimate the size of boats of known length. To be consistent with the whale measurements, we used 2 research vessels, which were photographed in the same locations and at the same time as photographic encounters with whales. Conveniently, these boats were the same approximate size as whales from

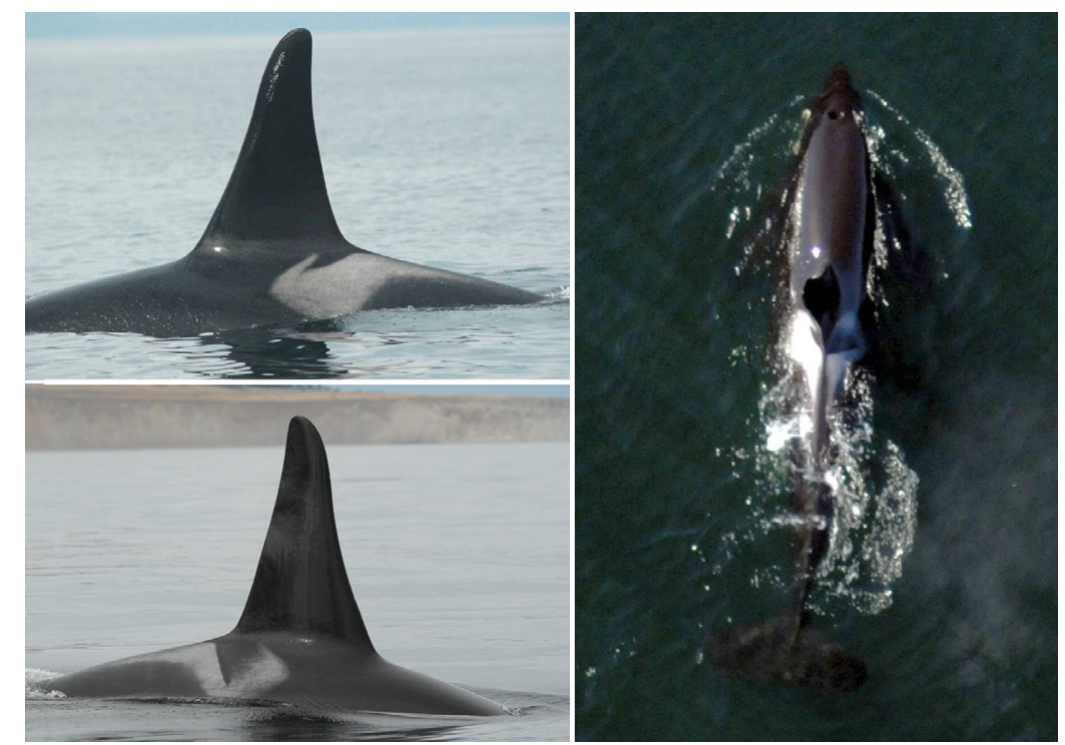

Fig. 1. Left-side (upper left panel) and right-side (lower left panel) identification photographs obtained from boat platforms of Whale L78, a male first seen as a young-of-the-year in 1989, displaying the distinctive saddle-patch pigmentation of southern resident killer whales Orcinus orca which is used to confirm identification from aerial images (right panel) 
this population (see 'Results'): one was a rigid hulled inflatable boat (RHIB) that measured $5.46 \mathrm{~m}$ and the other was a Boston Whaler measuring $6.50 \mathrm{~m}$, both measured from the tip of the bow to the back of the outboard engine.

Statistical analysis. Average growth trends of whales were examined by fitting a generalized logistic (termed 'Richards') growth curve (Richards 1959) to the size-at-age data for each sex, separately. This curve, describing the length at Age $t\left(L_{t}\right)$, is given by the equation:

$$
L_{t}=A[1-b \times \exp (-c t)]^{M}
$$

where $A$ is asymptotic adult length, $t$ is age in years, $b$ and $C$ are free parameters that adjust the slope and inflection point of the curve, and $M$ describes the relative position of the inflection point relative to the asymptote. The Richards curve is a generalization of the classical growth curves that are commonly used, such as the Gompertz curve (e.g. Read et al.1993, Webster et al. 2010), but with increased flexibility because the point of inflection is not in a fixed proportion to the asymptote (instead, its position depends on the parameter $M$ ). We were particularly interested in estimating the timing and value for the asymptote $(A)$ for each sex, as a measure of average adult size. Model fitting was accomplished using the method of non-linear least squares implemented using the $\mathrm{R}$ statistical package (www.r-project.org).

The ages of individually identifiable whales born since the start of the photo-identification study in the 1970s were based on long-term longitudinal birth and sighting records (Ford et al. 2000, K. C. Balcomb unpubl. data), and the age estimates of whales born prior to the start of the photo-identification study were based on the size development of dorsal fins for males and the age of oldest offspring for females, as described by Olesiuk et al. (1990, 2005) and presented in Ford et al. (2000). Following Olesiuk et al. (1990), ages were standardized by considering whales to be $0.5 \mathrm{yr}$ old in their first summer (May to September) census period. Sex was determined by visual observation of genital anatomy and pigmentation (e.g. Ford et al. 2000), by the development of sexual secondary characteristics in males (particularly the dorsal fin), or by the birth of a calf in females (Ford et al. 2000, K. C. Balcomb unpubl. data).

\section{RESULTS}

Aerial photographs were collected during 10 flights in September 2008. Flights lasted an average of $77 \mathrm{~min}$ (range: 61 to $118 \mathrm{~min}$ ), and whales were typically encountered in Haro Strait, off the west side of San Juan Island (Fig. 2). At least one of the research boats was photographed on each of 9 of the 10 total flights, with both boats being photographed on 1 flight, resulting in 147 measurable photographs of boats. There was some variability between length estimates of the same boat within days (Fig. 3), but this improved

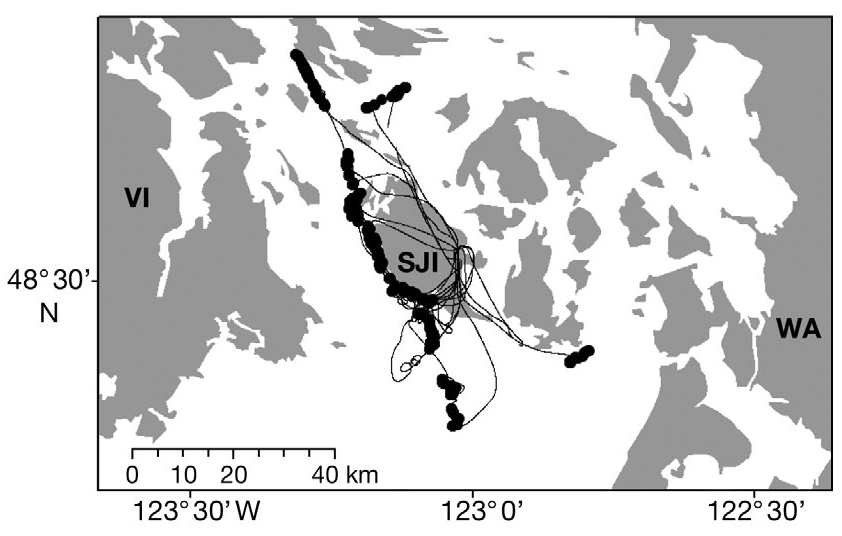

Fig. 2. Helicopter tracks (solid lines) and locations where measurement photographs of southern resident killer whales Orcinus orca were obtained (0) during the 10 photogrammetry flights from San Juan Island (SJI), located between mainland Washington State (WA) and Vancouver Island (VI)

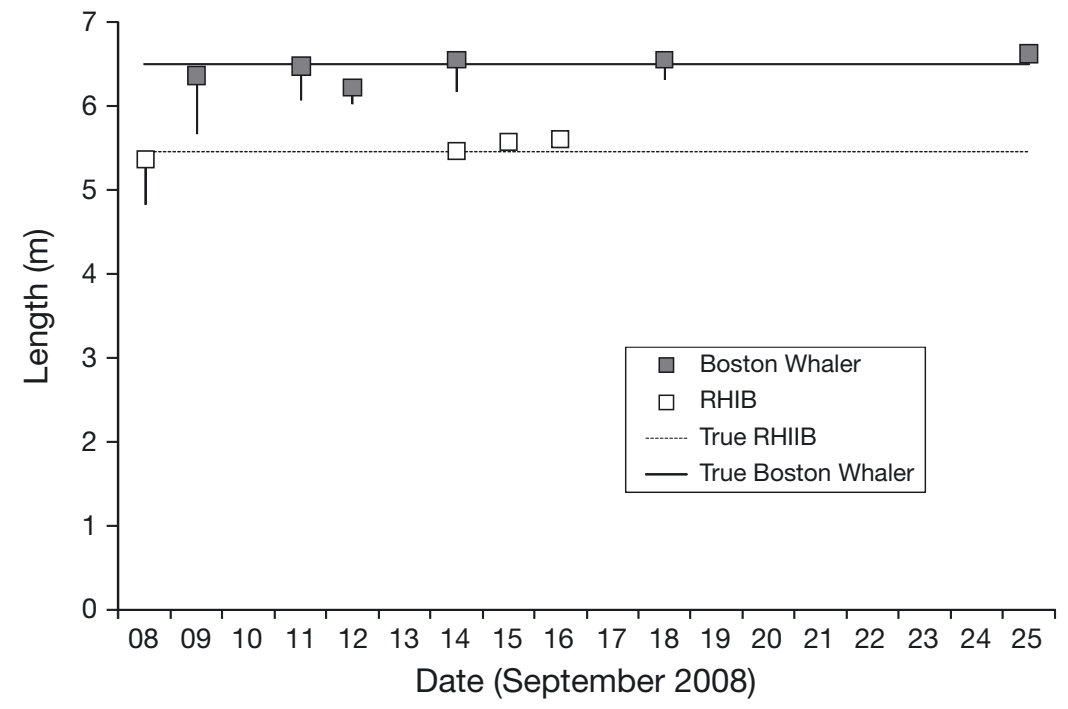

Fig. 3. Length estimates for the 2 research vessels, a rigid hulled inflatable boat (RHIB) and a Boston Whaler, on 9 different survey days, were used to calibrate the accuracy of aerial photogrammetry length measurements. Squares represent the best (maximum) estimate on each day, vertical lines represent the range of the variability between estimates within days, and horizontal lines represent the true size of each boat (5.46 $\mathrm{m}$ for the RHIB and $6.50 \mathrm{~m}$ for the Boston Whaler) 
across days as we quickly became better at positioning directly overhead of the research vessel, and selectively taking only vertical photographs. The maximum measurement for each boat was taken as the best estimate for that boat on each day, as smaller estimates were due to foreshortening as a result of photographs being taken when the boat was not directly under the helicopter. These estimates ranged from 5.41 to $5.57 \mathrm{~m}$ across days for the RHIB and 6.22 to $6.59 \mathrm{~m}$ for the Boston Whaler, representing an average bias of just $0.06 \mathrm{~m}$ (range: 0.02 to $0.10 \mathrm{~m}$ ) for the RHIB and $0.08 \mathrm{~m}$ (range: 0.00 to $0.28 \mathrm{~m}$ ) for the Boston Whaler, which represented an average of just $1.1 \%$ of the true length (range: 0.3 to $1.9 \%$ ) and $1.3 \%$ (range: 0.0 to $3.2 \%$ ) for each of the boats respectively, and a combined average of just $1.2 \%$ (Fig. 3).

Almost 3000 images (2803) were obtained, from which useable measurements were possible for 66 whales of known identification, comprising 35 females and 31 males. Whales were typically measured more than once (median: 7 surfacing sequences, range: 1 to 38). Variability within estimates of the same whale was likely due to a foreshortening effect of whales not being directly underneath the photographer and surfacing whales not being at their most elongated body position at the time of the photograph. The main bias was therefore likely to be negative, resulting in underestimates of length, and we thus chose to use the maximum estimate to be the best (least biased) for each whale. It should be noted, however, that even the maximum estimate may still have been negatively biased for full body length, and simply represented the longest body position measured for that whale. To reduce this effect, we only considered estimates to be reliable if measurements had been obtained from $\geq 5$ different images. All further analysis was based solely on the 46 whales for which this was the case (Table 1).

Estimated lengths ranged from a minimum length of $2.7 \mathrm{~m}$ for a neonate whale in its first year of life (Whale $\mathrm{K} 42$ ), to a maximum length of $7.2 \mathrm{~m}$ for a $31.5 \mathrm{yr}$ old adult male (Whale L41). Estimates of length showed an asymptotic relationship with age, for both males and females, illustrating growth in body length through the mid-teen years for females and the late teens for males (Fig. 4). The fitted Richards growth curve model estimated that adult males reached an average (asymptotic) size estimate $( \pm \mathrm{SE})$ of $6.9 \pm 0.2 \mathrm{~m}$, with growth slowing notably after an inflection point at the age $( \pm \mathrm{SE})$ of $18 \pm 4.7 \mathrm{yr}$; this was significantly larger than the asymptotic size of $6.0 \pm 0.1 \mathrm{~m}$ for females, which was reached between the measured ages of 14.5 and $18.5 \mathrm{yr}$, close to an inflection point at the age of $15 \pm$ $1.8 \mathrm{yr}$. These patterns are consistent with the ages of physical maturity based on repeated measures of dorsal fin growth in this population (Olesiuk et al. 1990),
Table 1. Length (tip of upper jaw to notch of flukes) estimates for southern resident killer whales Orcinus orca with $\geq 5$ measurements. Ages were estimated as per Olesiuk et al. (1990): birth year reflects the first May-September annual census period when present, at which time age was standardized to be 0.5 yr. Sex was determined by visual observation of genital anatomy and pigmentation (e.g. Ford et al. 2000), by the development of sexual secondary characteristics in males (particularly the dorsal fin), or by the birth of a calf in females (Ford et al. 2000, K. C. Balcomb unpubl. data). ID: identification number; F: female; M: male; Min.: minimum; Max.: maximum

\begin{tabular}{|c|c|c|c|c|c|c|}
\hline $\begin{array}{l}\text { Whale } \\
\text { ID }\end{array}$ & $\begin{array}{l}\text { Birth } \\
\text { year }\end{array}$ & $\begin{array}{l}\text { Age } \\
(\mathrm{yr})\end{array}$ & Sex & $\begin{array}{c}\text { No. of } \\
\text { measurements }\end{array}$ & $\begin{array}{l}\text { Leng } \\
\text { min. }\end{array}$ & $\begin{array}{l}\mathrm{h}(\mathrm{m}) \\
\max .\end{array}$ \\
\hline J41 & 2006 & 2.5 & F & 7 & 3.2 & 3.8 \\
\hline L103 & 2003 & 5.5 & F & 24 & 3.4 & 5.1 \\
\hline J37 & 2001 & 7.5 & F & 8 & 2.8 & 4.7 \\
\hline J36 & 2000 & 8.5 & F & 15 & 3.9 & 4.6 \\
\hline J35 & 1998 & 10.5 & F & 6 & 5.0 & 5.5 \\
\hline J31 & 1995 & 13.5 & F & 35 & 5.2 & 6.0 \\
\hline L91 & 1995 & 13.5 & F & 22 & 4.9 & 5.7 \\
\hline L94 & 1995 & 13.5 & F & 5 & 5.7 & 5.9 \\
\hline K27 & 1994 & 14.5 & F & 6 & 5.1 & 6.0 \\
\hline L82 & 1990 & 18.5 & F & 12 & 5.3 & 6.3 \\
\hline L83 & 1990 & 18.5 & F & 7 & 5.7 & 5.9 \\
\hline K20 & 1986 & 22.5 & $\mathrm{~F}$ & 14 & 5.7 & 6.2 \\
\hline L72 & 1986 & 22.5 & F & 8 & 5.3 & 5.6 \\
\hline J22 & 1985 & 23.5 & F & 14 & 5.0 & 5.5 \\
\hline L67 & 1985 & 23.5 & F & 18 & 5.4 & 5.7 \\
\hline J19 & 1979 & 29.5 & F & 15 & 1.2 & 5.8 \\
\hline J17 & 1977 & 31.5 & F & 13 & 5.2 & 6.1 \\
\hline K14 & 1977 & 31.5 & F & 6 & 5.5 & 6.4 \\
\hline L55 & 1977 & 31.5 & F & 23 & 3.7 & 6.2 \\
\hline J14 & 1974 & 34.5 & $\mathrm{~F}$ & 11 & 5.2 & 6.1 \\
\hline K13 & 1972 & 36.5 & $\mathrm{~F}$ & 12 & 5.5 & 6.2 \\
\hline K40 & 1963 & 45.5 & $\mathrm{~F}$ & 5 & 5.7 & 6.0 \\
\hline L7 & 1961 & 47.5 & $\mathrm{~F}$ & 7 & 5.6 & 6.2 \\
\hline K42 & 2008 & 0.5 & M & 8 & 2.4 & 2.7 \\
\hline L109 & 2007 & 1.5 & M & 9 & 3.2 & 3.6 \\
\hline L110 & 2007 & 1.5 & M & 10 & 3.2 & 3.5 \\
\hline K38 & 2005 & 3.5 & M & 8 & 3.4 & 3.9 \\
\hline L105 & 2005 & 3.5 & M & 6 & 3.5 & 3.9 \\
\hline J38 & 2003 & 5.5 & M & 28 & 3.2 & 5.2 \\
\hline J39 & 2003 & 5.5 & M & 8 & 4.1 & 4.8 \\
\hline K35 & 2003 & 5.5 & M & 14 & 4.1 & 4.8 \\
\hline K34 & 2002 & 6.5 & M & 17 & 3.9 & 4.4 \\
\hline J34 & 1998 & 10.5 & M & 16 & 5.1 & 5.8 \\
\hline J33 & 1996 & 12.5 & M & 5 & 5.7 & 5.9 \\
\hline L95 & 1996 & 12.5 & M & 8 & 5.1 & 5.9 \\
\hline J30 & 1995 & 13.5 & M & 17 & 4.1 & 6.1 \\
\hline K26 & 1993 & 15.5 & M & 5 & 6.2 & 6.5 \\
\hline J27 & 1992 & 16.5 & M & 38 & 5.4 & 6.5 \\
\hline K25 & 1991 & 17.5 & M & 30 & 5.0 & 6.1 \\
\hline L84 & 1990 & 18.5 & M & 8 & 5.8 & 6.5 \\
\hline L78 & 1989 & 19.5 & M & 20 & 6.4 & 7.0 \\
\hline K21 & 1986 & 22.5 & M & 7 & 6.1 & 6.5 \\
\hline L74 & 1986 & 22.5 & M & 14 & 6.2 & 6.7 \\
\hline L41 & 1977 & 31.5 & M & 32 & 6.1 & 7.2 \\
\hline L57 & 1977 & 31.5 & M & 7 & 5.2 & 6.7 \\
\hline J1 & 1951 & 57.5 & M & 10 & 5.7 & 6.8 \\
\hline
\end{tabular}

and we therefore followed these previous estimates to consider males of Age $21 \mathrm{yr}$ and older and females of Age $15 \mathrm{yr}$ and older to be adult in subsequent analyses. Notably, there was no overlap between the ranges of 


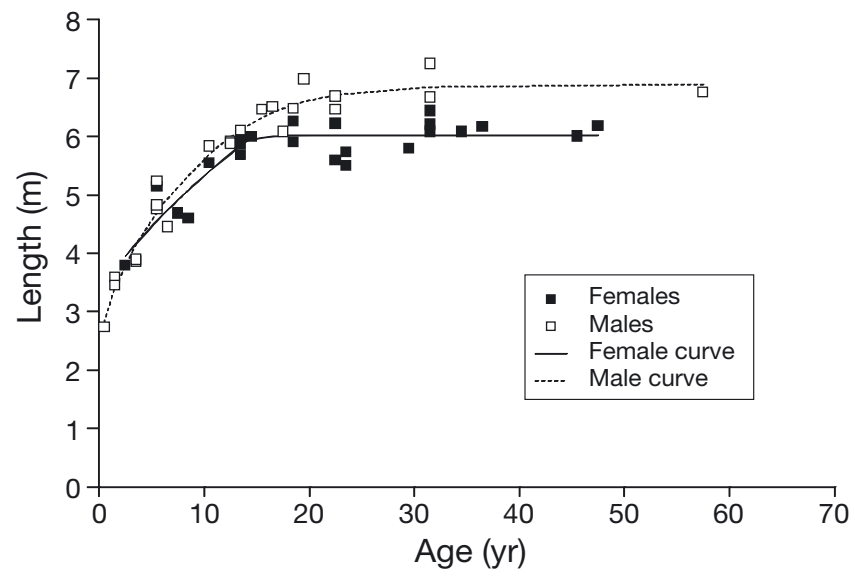

Fig. 4. Maximum estimate of length for southern resident killer whales Orcinus orca with $\geq 5$ measurement photographs, plotted against their observed or estimated ages. Ages were estimated as per Olesiuk et al. (1990); sex was determined by visual observation of genital anatomy and pigmentation (e.g. Ford et al. 2000), by the development of sexual secondary characteristics in males (particularly the dorsal fin), or by the birth of a calf in females (Ford et al. 2000; K. C. Balcomb unpubl. data)

estimated sizes of adult males (6.5 to $7.2 \mathrm{~m}$ ) and females $(5.5$ to $6.4 \mathrm{~m}$ ). Comparison of the lengths of older adults $(>30 \mathrm{yr}$ ) to the lengths of younger adults $(<30 \mathrm{yr})$ provided insight into long-term growth trends. On average, the older adults were $0.3 \mathrm{~m}$ ( $t$-test; $\mathrm{n}=14$, $\mathrm{p}=0.03)$ and $0.3 \mathrm{~m}(\mathrm{n}=5, \mathrm{p}=0.23)$ longer than the younger whales of adult age, for females and males, respectively.

\section{DISCUSSION}

Prior to our study, the available size data for southern resident killer whales came from a live-capture fishery (Bigg \& Wolman 1975), in which size-selectivity constrained a full assessment of the size structure of the population (Olesiuk et al. 1990). In the present study we used aerial photogrammetry to obtain length measurements from 66 whales, representing more than three-quarters of the population census of 83 whales in 2008 (Center for Whale Research unpubl. data). Whales of both sexes were measured, ranging in age from a first-year neonate to old adults for both males and females (Olesiuk et al. 1990). Despite selecting for smaller whales, the size of the largest male $(6.98 \mathrm{~m})$ and female $(6.25 \mathrm{~m})$ in the live-capture data (Bigg \& Wolman 1975) falls within the length ranges for adult males $(6.5$ to $7.2 \mathrm{~m}$ ) and adult females (5.5 to $6.4 \mathrm{~m}$ ) estimated in our study. This places southern resident killer whales at approximately the average size in the range of other killer whale populations throughout the world (Pitman et al. 2007).
Consistent and precise estimates of the length of research vessels of known size (and approximate whale size) served as an effective ground-truthing of our methods, with an average bias of just $7 \mathrm{~cm}(1.2 \%)$. Additionally, the asymptotic length-at-age curves for both males and females were consistent with ages of physical maturity for this population estimated from repeated measures of dorsal fin growth (Olesiuk et al. 1990). For females, a defined asymptote in growth was reached for all measured whales in the present study after the age of $14.5 \mathrm{yr}$, in close agreement with the previous estimate of female maturity at Age $15 \mathrm{yr}$. Although a small sample size of adult males constrained statistical power for curve fitting and prevented precise identification of the timing of the asymptote, there was notable slowing in growth after an estimated inflection point at $18 \mathrm{yr}$ old, in agreement with the previous estimate of physical maturity by Age 21 yr for male southern residents (Olesiuk et al. 1990) and after $18 \mathrm{yr}$ for males from the neighboring northern resident population (Olesiuk et al. 2005). These growth curves can now be used to convert size-at-age data to a total population weight, using existing length-weight relationships (Bigg \& Wolman 1975), and such mass calculations would provide key input into energetic calculations of food requirements (e.g. Noren 2011).

Energetic models for killer whales have previously relied on size assumptions for target populations based on published lengths from other killer whale populations (e.g. T. M. Williams et al. 2004, R. Williams et al. 2006), or mass from size-selective fisheries catches (e.g. Noren 2011), both of which may involve substantial bias that can be alleviated through the use of unbiased data from the target population. Furthermore, because the long-term photo-identification studies of southern resident killer whales have provided detailed demographic data on the age structure of this population in each of the past $37 \mathrm{yr}$ (Ford et al. 2009, Center for Whale Research unpubl. data), it is now possible to reconstruct estimates of the size, weight, and energetic requirements of the population at various times in the past and present. Understanding variability in the food requirements of this endangered population alongside patterns of variability in prey abundance would represent a significant contribution towards identifying risks and establishing conservation plans.

Our size-at-age estimates also provide an insight into long-term growth trends in this population. Notably, older adults were approximately $0.3 \mathrm{~m}$ longer than the younger whales of adult age, for both males and females. This difference was only significant for adult females, as our statistical power was limited by a small sample size of adult males available to be measured, as a result of relatively high adult male mortality in the mid-to-late 1990s (Krahn et al. 2004). This 
could represent continued somatic growth throughout life, as has been found in northern fur seals Callorhinus ursinus (Trites \& Bigg 1996), but we suggest that this may be an indication of nutritional stress in recent decades. Specifically, a long-term reduction in returning stocks of Chinook salmon (Beamish et al. 1995, Ford et al. 2009) may have reduced early growth rates and subsequent adult size in recent decades, alongside the reported decreases in survival (Ford et al. 2009), fecundity (Ward et al. 2009), and social cohesion (Parsons et al. 2009). Similar patterns have been observed in other vertebrate populations subject to nutritional stress: feral donkey Equus asinus populations exhibited a decrease in juvenile body condition and growth rate, and an increase in mortality, as a result of food shortages (Choquenot 1991); increases in mortality and decreases in growth rates for both Soay sheep Ovis aries and red deer Cervus elaphus have been found to be correlated with decreased food availability (Catchpole et al. 2000, 2004); and an observed decrease in survivorship, fecundity, and body length of Steller sea lions Eumetopias jubatus in Alaska has been linked to a decrease in the quality of available prey items (Trites \& Donnelly 2003).

As the time series of demographic monitoring of the southern resident killer whale population continues to extend, repeated assessments of size and growth in relation to food availability will allow an evaluation of this hypothesis, and may be an important tool for monitoring the success of management actions to protect prey resources.

Acknowledgements. This study was conducted with funding from the NOAA Northwest Regional Office, and we are grateful to L. Barre for her support and encouragement. We thank D. Armstrong of Friday Harbor Helicopters for excellent piloting and W. Perryman for technical advice. Staff at the Center for Whale Research assisted with fieldwork; J. Ford and R. Williams provided constructive comments on an earlier version of this paper. All aerial and boat-based operations around whales were conducted under the authority of permit \#532-1822 issued by the National Marine Fisheries Service.

\section{LITERATURE CITED}

Beamish RJ, Riddell BE, Neville CEM, Thomson BL, Zhang Z (1995) Declines in chinook salmon catches in the Strait of Georgia in relation to shifts in the marine environment. Fish Oceanogr 4:243-256

Bigg MA, Wolman AA (1975) Live-capture killer whale (Orcinus orca) fishery, British Columbia and Washington, 1962-1973. J Fish Res Board Can 32:1213-1221

Bigg MA, Olesiuk PF, Ellis GM, Ford, JKB, Balcomb KC III (1990) Social organization and genealogy of resident killer whales (Orcinus orca) in the coastal waters of British Columbia and Washington State. Rep Int Whal Comm Spec Issue 12:383-405
Breuer T, Robbins MM, Boesch C (2007) Using photogrammetry and color scoring to assess sexual dimorphism in wild western gorillas. Am J Phys Anthropol 134:369-382

Catchpole EA, Morgan BJT, Coulson TN, Freeman SN, Albon SD (2000) Factors influencing Soay sheep survival. Appl Stat 49:453-472

Catchpole EA, Fan Y, Morgan BJT, Clutton-Brock TH, Coulson T (2004) Sexual dimorphism, survival and dispersal in red deer. J Agric Biol Environ Stat 9:1-26

Choquenot D (1991) Density-dependent growth, body condition and demography in feral donkeys: testing the food hypothesis. Ecology 72:805-813

Durban JW, Parsons KM (2006) Laser-metrics of free-ranging killer whales. Mar Mamm Sci 22:735-743

Flamm RO, Owen ECG, Owen CFW, Wells RS, Nowacek D (2000) Aerial videogrammetry from a tethered airship to assess manatee life-stage structure. Mar Mamm Sci 16:617-630

Ford JKB, Ellis GM (2006) Selective foraging by fish-eating killer whales Orcinus orca in British Columbia. Mar Ecol Prog Ser 316:185-199

Ford JKB, Ellis GM, Balcomb KC III (2000) Killer whales: the natural history and genealogy of Orcinus orca in British Columbia and Washington State, 2nd edn. University of British Columbia Press, Vancouver

Ford JKB, Ellis GM, Olesiuk PF, Balcomb KC III (2009) Linking killer whale survival and prey abundance: food limitation in the oceans' apex predator. Biol Lett 6:139-142

Jaquet N (2006) A simple photogrammetric technique to measure sperm whales at sea. Mar Mamm Sci 22:862-879

Koski WR, Davis RA, Miller GW (1992) Growth rates of bowhead whales as determined from low-level aerial photogrammetry. Rep Int Whal Comm 42:491-499

Krahn MM, Ford MJ, Perrin WF, Wade PR, Angliss RP (2004) Status review of southern resident killer whales (Orcinus orca) under the Endangered Species Act. NOAA Tech Memo NMFS-NWFSC-62. Northwest Fisheries Science Center, Seattle, WA

> Landete-Castillejos T, Garcia A, Gomez JA, Laborda J, Gallego L (2002) Effects of nutritional stress during lactation on immunity costs and indices of future reproduction in Iberian red deer (Cervus elapus hispanicus). Biol Reprod 67:1613-1620

> Lee PC, Moss CJ (1995) Statural growth in known-age African elephants (Loxodonta africana). J Zool (Lond) 236:29-41

> Metcalfe NB, Monaghan P (2001) Compensation for a bad start: grow now, pay later? Trends Ecol Evol 16:254-260

Noren DP (2011) Estimated field metabolic rates and prey requirements of resident killer whales. Mar Mamm Sci 27: 60-77

Olesiuk PF, Bigg MA, Ellis GM (1990) Life history and population dynamics of resident killer whales (Orcinus orca) in the coastal waters of British Columbia and Washington State. Rep Int Whal Comm Spec Issue 12:209-244

Olesiuk PF, Ellis GM, Ford JKB (2005) Life history and population dynamics of northern resident killer whales (Orcinus orca) in British Columbia. Res Doc 2005/45. Canadian Science Advisory Secretariat, Fisheries and Oceans Canada, Ottawa. Available at www.dfo-mpo.gc.ca/csas/ Csas/Publications/ResDocsDocRech/2005/2005_045_e.htm

Parsons KM, Balcomb KC III, Ford JKB, Durban JW (2009) The social dynamics of the southern resident killer whales and implications for the conservation of this endangered population. Anim Behav 77:963-971

> Perryman WL, Lynn MS (1993) Identification of geographic forms of common dolphin (Delphinus delphis) from aerial photogrammetry. Mar Mamm Sci 9:119-137 
Perryman WL, Lynn MS (2002) Evaluation of nutritive condition and reproductive status of migrating gray whales (Eschrichtius robustus) based on analysis of photogrammetric data. J Cetacean Res Manag 4:155-164

Perryman WL, Westlake RL (1998) A new geographic form of the spinner dolphin, Stenella longirostris, detected with aerial photogrammetry. Mar Mamm Sci 14:38-50

Pitman RL, Perryman WL, LeRoi D, Eilers E (2007) A dwarf form of killer whale in Antarctica. J Mammal 88: 43-48

Read AJ, Wells RS, Hohn AA, Scott MD (1993) Patterns of growth in wild bottlenose dolphins, Tursiops truncatus. J Zool (Lond) 231:107-123

Richards FJ (1959) A flexible growth function for empirical use. J Exp Bot 10:290-300

Shrader AM, Ferreira SM, McElveen ME, Lee PC, Moss CJ, van Aarde RJ (2006) Growth and age determination of African savanna elephants. J Zool (London) 270: $40-48$

Editorial responsibility: Ana Cañadas,

Madrid, Spain
Trites AW, Bigg MA (1996) Physical growth of northern fur seals (Callorhinus ursinus): seasonal fluctuations and migratory influences. J Zool (London) 238:459-482

> Trites AW, Donnelly CP (2003) The decline of Stellar sea lions Eumetopias jubatus in Alaska: a review of the nutritional stress hypothesis. Mammal Rev 33:3-28

> Ward EJ, Holmes EE, Balcomb KC (2009) Quantifying the effects of prey abundance on killer whale reproduction. J Appl Ecol 46:632-640

Webster T, Dawson S, Slooten E (2010) A simple laser photogrammetry technique for measuring Hector's dolphins (Cephalorhynchus hectori) in the field. Mar Mamm Sci 26: 296-308

- Williams TM, Estes JA, Doak DF, Springer AM (2004) Killer appetites: assessing the role of predators in ecological communities. Ecology 85:3373-3384

Williams R, Lusseau D, Hammond PS (2006) Estimating relative energetic costs of human disturbance to killer whales (Orcinus orca). Biol Conserv 133:301-311

Submitted: July 20, 2010; Accepted: December 16, 2010 Proofs received from author(s): February 25, 2011 